\title{
Beyond Psychological Safety - the Role of Direct Supervisor Behavior in Fostering Learning from Errors at the Workplace
}

\author{
Laura Smeets $^{1}$ (D) Wim H. Gijselaers ${ }^{1}$ (D) - Roger H. G. Meuwissen ${ }^{2}$ (D) \\ Therese Grohnert ${ }^{1}$ (iD
}

Received: 17 July 2020 / Accepted: 16 June 2021 / Published online: 16 July 2021

(C) The Author(s) 2021

\begin{abstract}
This study explores how direct supervisors can hinder or enhance how professionals learn from their errors. Extant research has often focused on psychological safety as the main condition for this kind of learning to take place. We expand prior research by exploring which behaviors of direct supervisors effectively facilitate learning from errors in concert with psychological safety. We conducted semi-structured interviews among 23 professionals to gain detailed insights into their thoughts, needs, and the difficulties they encounter. Through content analysis, we identified four critical supervisor behaviors that participants viewed as facilitating learning from errors next to fostering a psychologically safe work environment: (1) providing timely feedback, (2) guidance and elaborate feedback, (3) being accessible and personally involved, (4) organizing joint evaluations. Based on our findings, recommendations are formulated for supervisors that aim to facilitate professionals' learning from errors and their professional development.
\end{abstract}

Keywords Learning from errors · Psychological safety · Supervisor behavior · Workplace learning

Human errors are a recurring outcome of organizational work (Dahlin et al., 2018; Reason, 1995; Seifried \& Höpfer, 2013), despite all efforts being made to prevent them

Laura Smeets

lh.smeets@maastrichtuniversity.nl

Therese Grohnert

t.grohnert@maastrichtuniversity.nl

1 Department of Educational Research and Development, School of Business and Economics, Maastricht University, Maastricht, The Netherlands

2 Department of Accounting and Information Management, School of Business and Economics, Maastricht University, Maastricht, The Netherlands 
(Keith \& Frese, 2011; Zhao \& Olivera, 2006). Once these errors occur, they can result in a set of negative consequences affecting the person (stress or feeling incompetent) or forcing an organization to modify its procedures (Zhao, 2011; Lei et al., 2016). In the worst-case scenarios, errors can even lead to severe outcomes causing the death of a patient during surgery, a plane crashing, or overlooking crucial corporate information during financial audits. Whatever the consequences are, in most cases, it requires organizations and individuals to search for root causes, to modify behavior and procedures, and to learn from these errors such that in the near future, prevention is possible.

Learning from errors requires that organizations and individuals develop a better understanding of the underlying causes of the error situation. Research has consistently demonstrated that errors can be considered as a key factor enabling professionals to acquire essential professional competence and expertise (Bauer \& Mulder, 2007; Leicher et al., 2013). Errors - under the condition that they result from deficiencies in the available knowledge - can trigger professionals to initiate learning, because they provide negative but informative feedback on what still needs to be learned (Michael Frese \& Keith, 2015; Keith \& Frese, 2011). In the present study, we define learning from errors as engagement in learning activities involving the reflection on the causes of an error and developing new work processes to avoid reoccurrence of the error (Bauer \& Mulder, 2007; Leicher \& Mulder, 2016; Leicher et al., 2013). Engagement in learning activities can be individually or socially shared with others such as supervisors and colleagues (Bauer \& Mulder, 2007). Individual learning activities enable professionals to develop a deeper understanding of why the error occurred (Hetzner et al., 2011). Social learning activities facilitate the development of shared knowledge and help to create solutions and strategies to prevent similar errors (Leicher et al., 2013; Leicher \& Mulder, 2016). Engagement in social learning activities creates not only an opportunity to analyze an error in retrospection, it also helps the individual to challenge one's own (limited) perspective and to understand the causes of an error in the broader organizational context (Grohnert et al., 2019). These benefits exceed those of individual learning activities, as professionals may gain insights that would have been difficult to realize without external input (Bauer, 2008). This study focuses on both individual and social learning activities, which are part of workplace learning (Billett, 2004; Eraut et al., 1998).

Enabling professionals to learn from their errors requires that social conditions have been met to deal with negative emotions such as shame and fear (Cannon \& Edmondson, 2005). Research has pointed out that if the negative consequences of errors keep being emphasized, professionals do not consider this as a fruitful opportunity to learn and improve their performance (Grohnert et al., 2019; Harteis et al., 2008). Not surprisingly, learning does not follow automatically from erring, because it requires professionals to talk openly about their errors and ask for help without fear of ridicule or reprimands made by their peers and supervisors. Edmondson's seminal work has consistently shown that it requires trust and safety within an organizational unit to overcome the negative connotations caused by errors (Edmondson, 2011; Edmondson, 1999). Otherwise, professionals will cover up their errors, deny what has happened, or persist in what they have done out of fear to get penalized in their work or career (Edmondson, 1999). 
Research by Edmondson (1999) and Frese and Keith (2015) have demonstrated that if the work environment is not perceived as psychologically safe, professionals try to avoid acknowledging that errors have been made or share their experiences with their colleagues or supervisors. Traditionally, psychological safety is a team-level construct and defined as "the shared belief held by members of the team that the team is safe for interpersonal risk-taking" (Edmondson, 1999, p.354). In their review Edmondson and Lei (2014) conclude that psychological safety is contingent with 1) performance, 2) learning behaviors at different organizational levels, and 3) with speaking up to supervisors who authorize the work being done. A meta-analysis by Frazier et al. (2017) identified a strong positive effect of psychological safety on triggering learning behaviors at both the individual and the team level. Taken together, a substantial body of research suggests that psychological safety is a dominant driver of learning from errors.

A growing amount of review studies and meta-analyses focus on how psychological safety can be created in work settings, and what behaviors are necessary to achieve it (Edmondson \& Lei, 2014; Frazier et al., 2017; Koeslag-Kreunen et al., 2018; Nellen et al., 2019). This research has repeatedly highlighted that leaders, especially direct supervisors, play a key role in shaping the perceptions of psychological safety. These supervisors role model desirable attitudes and behaviors when confronted with errors by demonstrating specific leader behaviors such as tolerating errors, admitting their errors, and exhibiting openness (e.g. Hirak et al. 2012; Zhao et al., 2018). While prior research has primarily focused on how leaders can create team psychological safety (Carmeli et al., 2012; Nembhard \& Edmondson, 2006), research has focused less on how leader behaviors are perceived and interpreted by supervisees for learning, specifically in a hierarchical context (for reviews, see Edmondson \& Lei, 2014; Newman et al., 2017). This paper focuses on the degree to which individuals experienced psychology safety in an error situation involving interactions with their supervisor, placing the individual at the center of understanding which conditions facilitate learning from errors.

To date, it remains an open question which other behaviors supervisors can use to enhance or hinder professionals' learning from errors. It is important to empirically address this question because extant research suggests that creating a psychologically safe work environment is a necessary, but not a sufficient condition for learning from errors (Baumgartner \& Seifried, 2014; Edmondson, 2019; Edmondson \& Lei, 2014). Though direct supervisor behavior has been recognized as an essential factor in learning from errors, little is known about how direct supervisors can help individual professionals to learn from their errors besides creating a psychologically safe work environment. Even less is known about how direct supervisors in dyadic relationships can enable professionals to learn from their errors. In this respect, Edmondson and Lei (2014) suggest that more research is necessary, providing insight into how psychological safety unfolds in asymmetric employee - supervisor relationships.

The present study focuses on how direct supervisors enhance or hinder professionals' learning from errors. By conducting semi-structured interviews, we explore which behaviors of direct supervisors can facilitate professionals' learning from errors in concert with creating a psychologically safe work environment. Exploring these questions adds to prior research in three ways. First, it provides an overview of learning activities that professionals use individually and socially shared to learn from their 
errors. As participants are asked to report which learning activities they used in reality, potential obstacles that hinder engagement in learning activities can be identified. Second, we expand research on learning from errors by developing new insights into how the immediate social context- that is the direct supervisor- plays a significant role in explaining whether and to what extent professionals learn from their errors. Third, it contributes to our understanding of how supervisors can help professionals to learn from their errors besides creating psychological safety. The remainder of this paper is organized as follows. First, we provide a theoretical overview in which we conceptualize learning from errors as engagement in learning activities. Next, we provide an overview of contextual conditions that have been found necessary for learning from errors to occur. After describing the research context and methods, we report our findings, including a discussion and implications for practice and future research.

\section{Theoretical Framework}

\section{Learning from Errors as Engagement in Learning Activities}

Conceptualizing learning from errors at work first requires the clarification of the concept "error". Drawing upon action-oriented approaches, we define errors as individual actions that result in an unintended deviation from a desired goal and that endanger the attainment of higher-order goals, including knowledge and rule-based errors, which have a high potential for learning (Frese \& Zapf, 1994; Rasmussen, 1987; Reason, 1995; Bauer \& Mulder, 2007; Leicher et al., 2013). In this study we take errors as the starting point. It is the moment in which an individual has recognized he or she made an error either by the professional themselves or through negative feedback received by the direct supervisor. In contextualizing learning from errors for this study, we build on experiential learning theory's (ELT) activity perspective that frames learning as a self-directed and self-organized effort to improve performance and focuses on learning in terms of the engagement in learning activities (Bauer, 2008; Bauer \& Mulder, 2007; Bauer, 2008; van Woerkom 2003). Based on ELT's conceptualization of learning as reflection-action cycles, learning from errors can be framed as the engagement in effortful learning activities involving (i) reflection on the causes of an error (ii), developing new work processes to avoid reoccurrence of the error, and (iii) the implementation of the new processes within the work context. Following this framework, we operationalize learning from errors as engagement in learning activities, involving professionals' reflection on the underlying causes of an error and the development of strategies to avoid similar errors in the future (Bauer \& Mulder, 2007).

Engagement in learning activities may take place individually or be socially shared (Bauer \& Mulder, 2007; Leicher \& Mulder, 2016; Leicher et al., 2013). Individual learning activities involve activities that are performed on one's own without input from others, such as reflecting on the underlying causes of errors (Harteis et al., 2008; Rybowiak et al., 1999). Literature on workplace learning highlights that engagement in individual learning activities provides opportunities to develop a deeper understanding of why a particular error occurred (Gartmeier et al., 2008; Hetzner et al., 2011) and to acquire (negative) knowledge (Gartmeier et al., 2008). At the same time, the role of social exchange for learning to occur has been emphasized in theories of workplace 
learning and professional development (Billett, 2004; Eraut et al., 1998). Workplace learning literature suggests that interaction with other people at work constitutes one of the most significant sources of learning at work (Bauer \& Mulder, 2013; Billett, 2004; Marsick and Watkins 2003). Engagement in social learning activities- such as jointly developing strategies to avoid similar errors - deliver opportunities to co-construct knowledge and to draw conclusions for future actions (Bauer \& Mulder, 2013; Cannon \& Edmondson, 2005). Professionals can benefit from social exchanges with knowledgeable others, as it might help them to extend their own perspectives, and gain insights that would be difficult to realize without external input (Bauer \& Mulder, 2013; Grohnert et al., 2019). Previous research that explored professionals' engagement in learning activities, focused on error experiences described by experts, and aimed to identify what professionals should do ideally to not repeat a similar error (Bauer \& Mulder, 2007). Adding to Bauer and Mulder's (2007) study, the present study explores what professionals explicitly have done after discovering their error to avoid reoccurrence in the future. The present study explores engagement in both individual and social learning activities after discovering an error, leading to our first research question:

Research Question 1. What type of individual and social learning activities do professionals engage in after discovering an error?

\section{Beyond Psychological Safety}

Although errors can be potentially fruitful for learning they are often associated with sanctions such as reduced career opportunities and the possibility of being fired (Keith $\&$ Frese, 2011). Not surprisingly, these negative error connotations may result in dysfunctional reactions such as ignoring the error, rather than engagement in learning activities (Edmondson, 1999; Frese \& Keith, 2015; Seifried \& Höpfer, 2013; Zhao \& Olivera, 2006). To overcome this barrier, professionals need to perceive their interpersonal work environment as tolerant towards errors - a psychologically safe working environment (Edmondson, 1999; Edmondson \& Lei, 2014). As such, psychological safety involves beliefs about how supervisors and team members will respond when one puts oneself on the line, for example by openly admitting an error, or asking for help (Edmondson, 1999; Nembhard \& Edmondson, 2006). It reduces the perceived costs of engaging in learning activities (Edmondson, 1999; Edmondson \& Lei, 2014).

However, researchers have begun to suggest that the perception of a psychologically safe work environment is a necessary, but insufficient condition to ensure learning from errors (Baumgartner \& Seifried, 2014; Cannon \& Edmondson, 2005; Cusin \& GoujonBelghit, 2019; Ye et al., 2018). In a review by Edmondson and Lei (2014), the authors argue that psychological safety is not a panacea for learning (from errors) to occur. More recently, Edmondson (2019) used the metaphor of "starting a car" to describe why psychological safety is not enough for learning to occur; psychological safety helps "to take off the brakes" that keep professionals from engaging in interpersonal risk behaviors such as seeking help from their supervisor, "but it is not the fuel that powers the car" (Edmondson, 2019, p. 21). Besides creating psychological safety, Edmondson (2019) argues that leaders have the vital task to coach and inspire their 
employees and to provide them with feedback. To date, Zhao et al.'s (2018) study is one of few examples of studies that explicitly look beyond psychological safety for promoting learning from errors. Therefore, it remains empirically underexplored which other supervisor behaviors impact professionals' learning from errors. This leads us to our second research question:

Research Question 2. Which supervisor behaviors foster the engagement in individual and social learning from errors activities, besides creating a psychologically safe work environment

\section{The Role of Supervisor Behavior for Learning from Errors}

According to Cannon and Edmondson (2005), psychological safety is not implemented through top- down command, but is created through attitudes and behaviors of local managers, supervisors, and unit leaders. Research has identified specific leadership behaviors that strongly influence professionals' perceptions of psychological safety, including admitting own errors, being accessible, and exhibiting openness (Cusin \& Goujon-Belghit, 2019; Edmondson, 2011; Edmondson \& Lei, 2014; Zhao et al., 2019). Leaders hold this unique position due to their social power: they control subordinates' job assignments and promotions, influencing their subordinates' attitudes and perceptions (Cannon \& Edmondson, 2005; Rodriguez \& Griffin, 2009; Detert and Burris 2007). Consequently, leaders are a central lever for creating a psychologically safe learning environment.

Next to the research on leadership and psychological safety, studies on learning (from errors) have also highlighted the importance of direct supervisor behavior. Existing theories and research highlight that learning from errors greatly depends on how leaders exert their leadership role (Bligh et al., 2018; Cannon \& Edmondson, 2005; Deng et al., 2010; Farnese et al., 2019; Rodriguez \& Griffin, 2009). For example, Grohnert et al. (2019) found that young professionals are more likely to seek help and to learn from their errors when their direct supervisor engages in learning behaviors themselves. Moreover, studies by Keith and Frese (2005) and Zhao (2011) found that professionals pay attention to their supervisors' behaviors and attitudes with regard to errors. Findings indicated that professionals who perceived their manager to be intolerant of errors were more likely to have strong negative emotional responses to errors and to be reluctant to engage in learning behaviors, such as discussing errors with their supervisor. These studies illustrate that supervisors' behaviors beyond creating psychological safety can both foster and inhibit professionals' learning from errors. Building further on this limited extant research and the central role that direct supervisors play for both psychological safety and learning from errors, we explore which specific direct supervisor behaviors hinder engagement in individual and social learning activities of supervisees, leading to our third research question:

Research Question 3. Which supervisor behaviors hinder the engagement in individual and social learning from errors activities, besides creating a psychologically safe work environment? 


\section{Methods}

\section{Setting and Sample}

The present study was conducted in the field of auditing. The audit profession is characterized by its high stakes, high societal relevance, and high complexity, (Gronewold \& Donle, 2011; Seckler et al., 2017). This field was chosen for two reasons. First, there is a substantial likelihood when making errors in judgement and decision-making which can have significant consequences. Second, auditors work in a proceduralized work environment requiring them to use standards and to rely on rules and regulations during an audit. Regulators assess whether audit work is in compliance with these regulations, and do not accept that errors occur because of ignoring these regulations (Grohnert et al., 2019; Gronewold et al., 2013). Auditors assess organizations' financial statements and provide assurance that the financial statements are in accordance with laws and regulations. The audit firm environment is hierarchically organized and relies on teamwork to cope with task complexity (Ater et al., 2019). These teams commonly comprise four ranks who are evaluated and receive feedback from the next higher rank (Jeppesen, 2007; Trotman et al., 2015). At the lowest rank, associates collect and explore evidence, mostly through standardized tasks and structures and document the audit work and findings in an audit file. Next, seniors review the work of the associates and provide them with feedback and help; they take on tasks that bridge different routine tasks and prepare information for decisions at higher ranks. Above the senior level, a manager is in charge of reviewing the work prepared at lower levels, followed by a final (more aggregate) review performed by the partner. The partner is responsible for eventually signing the audit opinion, issuing a judgment about the 'true and fair' view of the client's financial statements. Work in audit teams is thus characterized by cascading dyadic reviews throughout all hierarchical ranks, in which multiple team members are in supervisory roles. Consequently, we refer to seniors, managers, and partners as supervisors in this study. Within this hierarchical review structure, the role of supervisors can be described as formal leadership that is determined by work experience, training, and expertise enabling them to detect errors in the work of auditors in lower ranks (Gibbins \& Trotman, 2002).

Twenty-three professionals working in the domain of auditing participated in this study. First, we asked six professionals at the highest rank (partners) working at different audit firms to participate. When they agreed, these partners were asked to provide three or four additional names of colleagues working in lower ranks (e.g. managers, seniors and associates) to participate. Working this way, enabled us to get a sample representing all hierarchical layers. Therefore, the intended and realized sample in this design is identical. Our sample includes both male $(n=17)$ and female $(n=6)$ auditors across all hierarchical ranks (5 associates, 6 seniors, 6 managers, 6 partners), working for five different audit firms in the Netherlands. Work experience ranges from 2 to 32 years. By interviewing all hierarchical ranks, we develop a comprehensive understanding of how direct supervisors can help professionals to learn from their errors. 


\section{Interview Guideline and Procedure}

In the present study, we used a semi-structured interview approach to explore our theoretical framework along with leaving room for inductive findings. The interview guideline was developed based on Flanagan's (1954) Critical Incidents Technique (CIT) .A critical incident has been described as an observable complete human activity that can be used to predict behavior (Flanagan, 1954). Following the application of the CIT in prior studies on learning from errors (Anselmann \& Mulder, 2018; Bauer, 2008; Gartmeier et al., 2008), we asked interviewees to describe a recent situation in which they made an error that was either detected by themselves or through negative performance feedback by the direct supervisor. ${ }^{1}$ We decided to use the CIT as it allows to explore real error situations and subsequent engagement in learning activities (Mulder, 2015). This approach supplements studies that used vignettes (Johannes Bauer \& Mulder, 2013), where subjects need to be able to identify with a described error case and where it is unsure whether answers about the engagement in learning activities are valid for actual behavior.

We used a semi-structured interview approach, asking interviewees to describe a recent error situation. We focussed on three overall themes including: perceptions of psychological safety, engagement in learning activities after error discovery, and perceptions on how direct supervisors helped professionals to learn from their errors (see Appendix). To explore participants' perceptions of psychological safety we asked questions such as "how safe do you feel to openly discuss your errors with your direct supervisor?" To explore engagement in learning activities, we mirrored Bauer and Mulder's (2007) interview guideline and asked interviewees to describe what they specifically have done to prevent the same error. The interview questions were formulated in such a way, that using the term "learning" was avoided, because people tend to respond using the notion of formal learning and might not be aware how engagement in learning activities leads to the construction of new knowledge (Bauer \& Mulder, 2007; Simons \& Ruijters, 2004). To test the interview guideline for clarity and completeness, a pilot interview was conducted with two experts in the field of auditing who both had more than ten years of experience and worked in a supervisor role (in line with Bauer \& Mulder, 2007; Leicher et al., 2013). Based on the pilot, we provided definitions and examples for errors to participants and were able to use professional jargon to ask more precise and relevant questions within the audit context. The full interview guideline is reported in the Appendix.

Interviews were conducted between May and July 2018. They lasted one hour on average and were carried out at the workplace of the interviewees. Before each interview started, interviewees were given a short introduction to the research topic (see Appendix) and permission was obtained from all interviewees to audiotape the interview. We assured anonymity to the interviewees and their employing organization by removing identifying data (e.g. interviewees' names and their employing organization). Following Francis et al. (2010), we decided that the point of saturation had been reached when after 10 interviews, the next five further interviews in the analysis

\footnotetext{
${ }^{1}$ The majority of our interviewees reported an error which they described as a consequence of their way of working (i.e. the audit review process). Consequently, we are unable to contrast findings for self-detected and supervisor detected errors.
} 
showed no new emergent themes. After the first twenty interviews, we reached saturation: auditors converged in their views, without adding more information emerging from, the remaining interviews.

\section{Analysis}

Interviews were transcribed verbatim and analyzed through directive content analysis (Hsieh \& Shannon, 2005), relying on both deductive and inductive coding. In this study, the meaningful unit of analysis consisted of a "multiple chunk" (Miles \& Huberman, 1994) and represented a sentence, a part of a sentence, or a set of related sentences. Interviews were coded and analyzed using the ATLAS.ti 8 program in three successive steps. First, transcripts were coded deductively based on the interview themes (see Appendix). Second, segments that could not be coded were analyzed and were inductively assigned to a new code or sub-code. Third, intercoder reliability was tested. Following Miles and Huberman (1994), a peer researcher was trained to independently code $10 \%$ of the randomly selected meaningful segments per transcripts through blind coding (Schreier, 2012). After each transcript, differences were discussed until agreement was reached, and modifications were made. The process resulted in a high level of intercoder reliability (Cohen's kappa =.84). Data for this study have been collected in Dutch, therefore the quotes that appear below were translated into English. ${ }^{2}$

\section{Results}

The present study focused on one category of errors: knowledge and rule-based errors. Concrete examples of this category include collecting incomplete audit evidence, not employing the appropriate audit procedure, and errors in interpreting evidence. These errors typically occur due to a deficiency in the available knowledge, and as such are mostly detected by the direct supervisor. All participants described errors that were detected in time and therefore could be corrected before threatening audit quality. The described errors contained little variation in terms of causes and consequences. Consequently, we did not make subcategories for the described errors but treated them as one category in the analysis.

\section{Research Question 1: Individual and Social Learning Activities}

The first research question explores what type of activities professionals engage in to learn from errors, and to what extent those strategies are performed individually or socially shared (see Table 1). We observed that most interviewees described individual learning activities (38 out of 65 statements): (1) thinking of alternative approaches, (2) recognizing error recurrence, and (3) revisiting prior work. Social activities were mentioned fewer times (27 out of 65 statements): (1) joint identification of alternatives, (2) interaction with supervisor, and (3) sharing the error with colleagues. We observed this trend across all ranks.

\footnotetext{
${ }^{2}$ Quotes in the original Dutch can be obtained from the first author.
} 
Table 1 Individual and social learning activities interviewees engaged in after discovering an error

$\begin{array}{ll}\text { Activity } \quad \text { Example statements } & \mathrm{n} / \mathrm{s}\end{array}$

Panel A. Engagement in Individual Learning from Errors Activities

(1) Formulating alternative approaches

(2) Recognizing error recurrence

(3) Revisiting prior work
"And now, I know for the next time that I do not have to include certain attachments to the client. Moreover, I learned that I need to formulate that sentence somewhat differently and that I need to pay attention to the confirmation" (Associate, 018).

"The next time something like this comes up again will most likely be 9/13 next year at the same client. Because I report changes in the file, I have a guarantee that I will remember it. When I open the file again in the upcoming year, I can see how the process went and what kind of feedback comments were made. This is an automatic guarantee for myself, on that specific audit engagement. Like, please be aware, you need to pay special attention to this" (Manager, 009).

"I went through my other prior work to see whether I made a similar $3 / 5$ mistake elsewhere. Those are things that need to be done." (Manager, 005).

Panel B. Engagement in Social Learning from Errors Activities

(1) Joint development of new "We had a team evaluation. We discussed the process. Moreover, we action strategies discussed what went wrong this year and how we can do better next year" (Senior, 014).

(2) Joint analysis

"I sat together with my supervisor, in which he explained why something was wrong. In that sense, he has trained me" (Senior, 014).

(3) Sharing the error with colleagues

"I have pointed out my error to other novices. Like, you must also explain this and this with everything you have done. So, if you execute audit work at the customer, make sure that you pay attention to this, otherwise, you will get the same feedback as I did" (Associate, 015).

$n$ number of answering interviewees, $s$ number of statements

\section{Engagement in Individual Learning Activities}

The most frequently mentioned strategy that interviewees used includes thinking of alternative approaches at the individual level ( 25 out of 65 statements, $n=16$ ). This involves drawing an appropriate conclusion on what to do differently next time through reflective activities like paying more attention to the correct documentation of clientspecific information. One interviewee explicitly referred to keeping a notebook in which she wrote down what went wrong and what should be done differently next year to avoid the same error from occurring. In this case, the auditor also applies the method of thinking backward to formulate ways about what to do differently next time. None of these sixteen interviewees mentioned during the interview what kind of drawbacks the strategy of thinking of alternative ways at the individual level can have. Concerning differences in rank, our results show that higher-ranking auditors tend to formulate process-wise learning activities, while lower-ranking auditors tend to formulate technical activities. Example quotes for this first individual learning activity across ranks can be found in Table 1 Panel A. 
The second most commonly identified strategy by interviewees, concerns the individual effort to remember the error situation to be able to recognize a similar situation in the future (13 out of 65 statements, $n=9$ ). Professionals across all ranks indicated that they try to remember what went wrong and how they have corrected the error. All interviewees stressed that this effort entails recording the errors, as this enables them to remember what went wrong and to identify what they need to pay attention to in the future. Additionally, two of the nine interviewees specifically mentioned that they memorize what went wrong by remembering specific task characteristics. This enables them to recognize specific task characteristics when performing similar tasks for other clients. Our results suggest that there are no differences between higher and lower ranks with regard to this strategy. Quotes illustrating this second individual learning activity are reported in Table 1 Panel A.

The individual learning activity encompasses an individuals' effort to revisit his or her work ( 5 out of 65 statements, $n=3$ ). Three higher-ranking auditors described examples of instances in which they revisited their prior work after correcting for errors. All three interviewees emphasized that it was aimed to check whether other work files did not contain the same errors. One interviewee explained that after his supervisor discovered an error in his work, he doubted whether he had performed well on other audit engagements. As a result, the person checked their prior work for other clients to ensure that they did not make the same error (see Table 1 Panel A).

\section{Engagement in Social Learning Activities}

The most frequently mentioned learning strategy performed in social interaction involves joint identification of possible alternatives for future action (12 out of 65 statements, $n=9$ ). This includes jointly thinking and formulating strategies about what to do differently next time in a similar situation. Interviewees across all ranks described instances in which they jointly identified alternatives for future action. All nine interviewees indicated that this took place in an informal evaluation session, including all team members. In most cases, an evaluation session's goal was to focus on what went wrong during the audit, and how to improve for next time. One interviewee indicated that the evaluation session took place in the daily team meeting, where the supervisor created room for discussing issues and asking other team members for help. Illustrative quotes can be found in Table 1 Panel B.

The second most commonly used social strategy that interviewees identified includes joint analysis (8 out of 65 statements, $n=7$ ). This activity includes a shared discussion with the direct supervisor on why an error occurred and how the individual can improve for the next audit. Six of the seven interviewees reported having initiated this conversation themselves. This learning activity was reportedly used mostly by lower-ranking auditors (see Table 1 Panel B).

The third social activity involves sharing the error with other colleagues to make sure that they can learn something too from one's error experiences (four out of 65 statements, $n=4$ ). This activity pertains to colleagues at the same rank so that they would not make the same error. One interviewee explained that they specifically shared the error with colleagues who had just started their career within auditing to prevent them from making the same errors (see Table 1 Panel B). 


\section{Research Question 2. Which Supervisor Behaviors Foster the Engagement in Individual and Social Learning from Errors Activities, besides Creating a Psychologically Safe Work Environment?}

The second research question explores which behaviors of direct supervisors can impact the engagement in learning from errors activities. Focusing on factors that enhance learning from errors, we explore which behaviors participants mentioned in relation to creating psychological safety and beyond. Interviewees described a psychologically safe work environment as an environment that encourages professionals to speak openly about their errors and to use their errors for learning. Fourteen interviewees described situations of high psychological safety, and we identified four elements that characterize a psychologically safe work environment: (1) being tolerant towards errors, (2) exhibiting openness, (3) modeling fallibility, and (4) physical presence (see Table 2 Panel A). Beyond psychological safety, we identified four main behaviors that foster engagement in learning from errors activities: (1) timely feedback, (2) providing guidance and elaborate feedback, (3) being accessible and showing personal involvement, and (4) organizing joint evaluations (see Table 2 Panel B). Below, we describe each behavior in turn.

\section{Direct Supervisor Behavior for Psychological Safety}

The most frequently mentioned direct supervisor behavior that enhances psychological safety is being tolerant towards errors (17 out of 38 statements, $n=12$ ). Twelve interviewees perceived their supervisor to be tolerant towards errors, rather than sanctioning. Those interviewees believed that they will not be humiliated or penalized by their supervisor when making an error. One manager described an episode in which an error was communicated to the supervisor, who reacted by being understanding and acknowledging that the error was reported so that the error could be resolved together as soon as possible. This reaction encourages the supervisee to show fallibility and to communicate their errors (for quotes, see Table 2 Panel A). With regard to cooccurrences, being tolerant towards errors co-occurs more often with social learning activities (21 co-occurrences) than with individual learning activities (10 co-occurrences).

The second direct supervisor behavior was exhibiting openness (5 out of 38 statements, $n=5$ ). Interviewees in a supervisory position, pointed out that they intend to exhibit openness by making statements such as "I have an open-door policy". Also, three interviewees in a non-supervisory position mentioned that their supervisor created psychological safety by exhibiting openness (see Table 2 Panel A). Regarding the cooccurrences, data showed that exhibiting openness predominantly promotes engagement in social learning activities (8 co-occurrences).

Next, modeling fallibility was identified as an effective behavior for enhancing psychological safety ( 6 out of 38 statements, $n=4$ ), mostly by higher-ranking interviewees. Supervisors display fallibility when admitting their errors and revealing their limitations. One senior explained that they feel safe to admit to errors under the condition that supervisors also display fallibility and openly admit their errors (see Table 2 Panel A). Concerning co-occurrences, data reveal few co-occurrences for both individual (4 co-occurrences) and social learning activities (1 co-occurrence). 
Table 2 Direct supervisor behaviors that enhance engagement in learning errors activities

Leader Behavior $\quad$ Example statement $\quad n / s$

Panel A. Leader behaviors enhancing psychological safety

(1) Being tolerant towards errors "Yes, it is accepted in any case. People do not react weirdly when $12 / 18$ it occurs" (Senior, 020).

(2) Exhibiting openness

"I simply tell people that the door is open. This lowers the barrier $5 / 5$ to approach me" (Partner, 012).

(3) Modeling fallibility

"I think it is important to show at certain moments that I do not $\quad 4 / 6$ know certain things myself. It is about demonstrating that I cannot do everything better myself' (Manager, 021).

(4) Physical presence

"I always try to be physically present. I need to show my face to $10 / 7$ the team. I often ask my team members "how is everything going?", because this lowers the threshold for people to ask questions. Otherwise, people often do not dare to ask anything" (Manager, 019).

Panel B. Leader behaviors enhancing learning from errors

(1) Timely feedback

(2) Being accessible and showing personal involvement

(3) Providing guidance and elaborate feedback

(4) Organizing joint evaluations
"The most effective feedback is provided immediately when something is going wrong" (Partner, 007).

"According to my experience, some supervisors should spend more time with the team, just as I do. This does not happen very often" (Manager, 021).

"More time needs to be planned for presence with the team. It does show commitment when the supervisor makes the effort to be present for two days a week" (Senior, 024).

"In my role, I need to guide younger professionals by ensuring that they can do a good job. Not perfect, but good enough. When one spends more time on guidance, it also means that the quality of the work will improve" (Senior, 001).

"During the assignment, I know that there is a lack of time. But as a supervisor, I try to make time for guiding my supervisees. During the busy season, it is very difficult for supervisors to provide effective guidance" (associate, 023).

"What you need for evaluating is being together and evaluating what could be improved. It can provide relevant input" (Manager, 021).

$n$ number of answering interviewees, $s$ number of statements

Lastly, physical presence was highlighted by interviewees in supervisory positions (10 out of 38 statements, $n=7$ ). The interviewees explained that being physically present lowered the barrier for supervisees to approach their supervisor for help (for illustrative quotes, refer to Table 2 Panel A). The data on physical presence also illustrated few co-occurrences for both individual learning activities (3 cooccurrences) and social learning activities (5 co-occurrences).

\section{Direct Supervisor Behavior for Engagement in Learning from Errors Activities}

The most frequently mentioned direct supervisor behavior that fosters engagement in learning activities was the provision of timely feedback (10 out of 35 statements, $n=8$ ). 
All interviewees agreed that performance feedback is most effective for learning when it is given promptly. Particularly lower-ranking interviewees emphasized this behavior $(n=5)$. In our study, performance feedback refers to information on discrepancies between the present and desired situation. One interviewee explained that timely performance feedback allowed supervisees to correct their errors immediately, and allowed other colleagues to potentially learn from the feedback too. From the supervisor's perspective, three supervisors commented that timely feedback is vital for learning, but that this issue requires more work (for quotes illustrating this behavior, refer to Table 2 Panel B). Regarding co-occurrences, our data demonstrated that timely feedback seems to be equally important for engagement in individual (9 co-occurrences) and social learning activities (6 co-occurrences).

The second most frequently mentioned direct supervisor behavior involves being accessible and personally involved (11 out of 35 statements, $n=7)$. Accessibility refers to the availability of the supervisor and being easy to reach. Lower-ranking interviewees explained that supervisors who make an effort to be regularly present, show involvement to the team and at the same time lower the barrier for approaching them to ask for help or feedback. One associate highlighted the need for verbal statements and behaviors to match: even when a supervisor encourages asking questions or requesting help, being physically absent decreases the chance that supervisees will actually engage in these social learning activities. From the supervisor's perspective, three interviewees claimed that supervisors need to make an effort to be physically present, show their involvement, and provide timely and effective feedback. The need for being accessible and involved is thus a shared perception across ranks (see Table 2 Panel B). Regarding co-occurrences, data revealed few co-occurrences for both individual learning activities (1 co-occurrence) and social learning activities (2 co-occurrences).

The third direct supervisor behavior that enhances learning from errors is providing guidance and elaborate feedback (8 out of 35 statements, $n=7$ ). Interviewees across ranks explicitly stated that it is the role of the supervisor to invest sufficient time in providing elaborate feedback and to guide supervisees in their learning process. One supervisor explained that there are two ways of providing feedback: information on 'what' is wrong and taking the time to provide in-depth explanations on why something went wrong. The first approach is highly efficient in the short term, but the second approach actively improves the competence and performance of supervisees over time. A manager emphasized that it only takes three minutes to provide elaborate feedback that can contribute to his supervisees' learning and professional development (see Table 2 Panel B). Analysis of co-occurrences revealed that providing guidance and elaborate feedback is important for both individual learning activities ( 9 co-occurrences) and social learning activities (6 co-occurrences).

The final direct supervisor behavior that enhances learning from errors is organizing joint evaluations ( 6 out of 35 statements, $n=5$ ). Joint evaluation refers to the effort to bring together the team to discuss what worked well and what did not work well, and what needs improvement for next time. Mostly higher-ranking interviewees stated that bringing together the team for reflective activities and to share (error) experiences is crucial to learn from each other's experiences. One supervisor explained that having a joint evaluation helps team members to comply with regulations and to meet quality requirements (for quotes see Table 2 Panel B). Concerning co-occurrences, our data revealed that organizing joint evaluations is crucial for both engagement in individual (7 co-occurrences) and social learning activities (4 co-occurrences). 


\section{Research Question 3: Which Supervisor Behaviors Hinder the Engagement in Individual and Social Learning from Errors Activities, Besides Creating a Psychologically Safe Work Environment?}

The third research question focuses on direct supervisor behaviors that hinder psychological safety and engagement in learning from errors activities. First, we identified two supervisor behaviors that hinder psychological safety: (1) being intolerant of errors, and (2) creating a threshold to sharing errors (see Table 3 Panel A). Second, we distilled four behaviors that hinder learning from errors directly, which are the opposite of those behaviors enhancing learning from errors: (1) lack of guidance and elaborate feedback, (2) lack of accessibility and personal involvement, (3) lack of timely feedback, and (4) lack of joint evaluation (see Table 3 Panel B). We describe these behaviors in turn.

Table 3 Direct supervisor behaviors that hinder engagement in learning from errors activities

\begin{tabular}{|c|c|c|}
\hline Leader Behavior & Example statement & $\mathrm{n} / \mathrm{s}$ \\
\hline
\end{tabular}

Panel A. Leader behaviors hindering psychological safety

(1) Being intolerant of errors "If you make such errors more often, you will hear about this during 6/12 your annual performance interview. And in turn, it affects your overall performance evaluation and even your salary". (Senior, 006)

(2) Creating a threshold to sharing errors

"Sometimes there are things that I think I should know about by now, so I do not want to ask about those. In those cases, I experience a small threshold" (Senior,022).

"One of my supervisors has a very hierarchical attitude. Everything seems to go well in his work. When I make an error in my work, he becomes angry and responds in an intimidating manner. As a result, I feel a barrier to approach my supervisor" (Senior, 020).

Panel B. Leader behaviors hindering learning from errors

(1) Lack of guidance and elaborate feedback

(2) Lack of timely feedback

(3) Lack of accessibility and personal involvement

(4) Lack of joint evaluation
"So, if I ask my supervisor something, he responds that he has five deadlines tomorrow. Then I try as much as I want, but I do not get help. I have once told my supervisor that this time pressure also hinders those who work for him in their development, because he cannot give them the attention they deserve" (Associate, 018).

"Especially when they execute something for the first time, I should already provide them with feedback the next day. In that case, the learning effect will be the greatest for them, and it enables them to apply immediately what they have learned" (Senior, 020).

"For example, I have a supervisor who is really hard to reach, he never answers his phone, does not respond to his email. I find this very annoying" (Senior, 008).

"Each time after an assignment, we need to sit together to discuss what went well and what did not go well. This is not done often enough. Due to time pressure, people forget about it and start working on the next assignment. An evaluation should be done more often. We need a mirror to do this. Often, people think that evaluations should rather be done at a later time" (Manager, 019). 


\section{Direct Supervisor Behaviors Hindering Psychological Safety}

Being intolerant of errors was identified by interviewees of lower ranks as the main behavior that hinders psychological safety (12 out of 17 statements, $n=6$ ). This behavior was associated with the fear of receiving sanctions from their supervisor when making errors. A senior explicitly described that their supervisor tends to react very angrily when hearing about an error. This interviewee observed the supervisor to have a hierarchical attitude and to not show any fallibility. As a result, the supervisee is afraid to make and share errors (illustrative quotes in Table 3 Panel A). For cooccurrences, data demonstrated a few co-occurrences for both individual learning activities (5 co-occurrences) and social learning activities (3 co-occurrences).

The second direct supervisor behavior hindering psychological safety was creating $a$ threshold to sharing errors ( 5 statements out of $17, n=3$ ). This threshold makes lowerranking interviewees afraid of being thought of as incompetent or ignorant, because the same supervisor will later assess their performance and decide whether they will get a promotion or not. Analysis of co-occurrences revealed few co-occurrences for both individual learning activities (4 co-occurrences) and social learning activities (4 cooccurrences). For illustrative quotes on this behavior, please refer to Table 3 Panel A.

\section{Direct Supervisor Behaviors Hindering Engagement in Learning from Errors Activities}

Engagement in learning from errors activities was perceived by interviewees to be most hindered by a lack of guidance and elaborate feedback (16 out of 68 statements, $n=$ 10), the opposite of enhancing safety. This behavior was discussed by interviewees of all ranks. Five lower-ranking interviewees reported that they receive insufficient guidance and feedback, which they felt was due to their supervisors' high workload. Three interviewees mentioned that their supervisor only indicate in their feedback what needs to be improved (in terms of specific instructions for correction), but not why it needs to be improved. As a result of this, supervisees were less likely to develop new insights on the causes of their errors. Three supervisors recognized their colleagues' needs and confirmed that their high workload and focus on clients were reasons. One supervisor explained that due to insufficient capacity, they are too busy with executive activities, even though they would like to provide more guidance. For illustrative quotes, refer to Table 3 Panel B. Concerning co-occurrences, we found that a lack of guidance and feedback is detrimental for both individual learning activities (19 cooccurrences) and social learning activities (8 co-occurrences).

The second most-frequently mentioned direct supervisor behavior that hinders learning from errors was identified to be a lack of timely feedback (18 out of 68 statements, $n=12$ ). Mostly lower-ranking interviewees provided examples of instances in which they received delayed feedback from their supervisor, up to one month later. Delayed feedback was considered a barrier for learning, as it limits professionals to remember how they have performed certain tasks, which in turn limits their ability to ask substantive questions and engage in an in-depth analysis of the underlying causes of errors. Supervisors acknowledged that it is their task and responsibility to provide their supervisees with timely feedback, however, this lack of timely feedback was due to the same reasons as for the lack of guidance and elaborate feedback: time pressure, workload, and a client focus (see Table 3 Panel B). Analysis of co-occurrences 
demonstrated that a lack of timely feedback more often co-occurs with individual learning activities (18 co-occurrences) than social learning activities (14 cooccurrences).

Thirdly, direct supervisors who are inaccessible and uninvolved also hinder learning from errors ( 10 out of 68 statements, $n=9$ ). Mostly lower-ranking interviewees stated that their supervisor makes insufficient effort to be regularly physically present, preventing them from seeking help. One senior commented that their supervisor does not show any personal involvement at all and provided the example of the supervisor not picking up the phone when called. Consequently, the senior described preferring to solve issues herself, not due to fear of the supervisor, but out of convenience. Again, time pressure and a focus on client were revealed to impede accessibility and involvement at higher ranks (see Table 3 Panel B). Regarding co-occurrences, data showed that a lack of accessibility and involvement more often co-occurs with individual learning activities (8 co-occurrences) than social learning activities (4 co-occurrences).

Finally, a lack of joint evaluation with a direct supervisor hindered learning from errors ( 10 out of 68 statements, $n=7$ ). One partner explained that he recently organized a joint evaluation with the whole team to discuss how to prevent similar errors from occurring the following year. The partner highlighted that this joint evaluation contributed to his team members' learning, but acknowledged that they should be done more often. This interviewee and four other interviewees confirmed that due to a lack of time and placing less priority on a joint evaluation, it is performed less often than it should be done. Concerning differences in rank, it was found that only higher-level auditors identified a lack of joint evaluations as a barrier for learning (see Table 3 Panel B). Regarding co-occurrences, data suggested that a lack of joint evaluations is detrimental for both engagement in individual learning activities (6 co-occurrences) and social learning activities (8 co-occurrences).

\section{Discussion}

The present study explored in detail how and when supervisors in dyadic relationships, enhance or hinder professionals' engagement in individual and social learning from errors activities. Through semi-structured interviews with professionals across ranks in the field of auditing, we addressed three research questions: which individual and social learning activities do professionals engage in after discovering an error, which behaviors by direct supervisors impact this engagement either directly or through psychological safety, and which behaviors hinder engagement in learning activities. Below, we discuss our key findings, along with limitations and implications for future research and workplace practice.

Regarding our first research question, we found that most interviewees reported engaging in individual learning from errors activities, such as formulating alternative approaches, recognizing error recurrence, and revisiting prior work. Social learning activities, such as shared brainstorming of alternative approaches and sharing errors, were mentioned fewer times throughout the interviews. This finding is in contrast with previous studies that emphasize the need for social activities over individual activities for effective learning from errors (Bauer \& Mulder, 2007; Harteis et al., 2008), Particularly, professionals in the early stages of their careers can profit from social 
exchanges with knowledgeable supervisors, because they may lack necessary knowledge for understanding the causes of their errors and how to learn from them (Bamberger, 2009; Shute, 2008). This finding may be context-specific as interviewees working in audit firms may encounter more direct supervisor behaviors that hinder learning from errors because of high time pressure, and client focus at the supervisor level, making it less likely that they engage in social learning from errors activities after making an error. Future research may benefit from comparing the engagement in individual and social learning activities across contexts to specify environmental drivers and barriers to learning from errors.

Our second research question focused on the direct supervisor behaviors that participants identified to enhance the engagement in learning from errors activities. For enhancing learning, our results confirm the important role that supervisors play in enabling professionals' learning from errors through creating a psychologically safe work environment by tolerating errors, exhibiting openness, modeling fallibility, and being physically present. These results corroborate the findings of previous research on psychological safety (for a review, see Edmondson \& Lei, 2014), making specific leader behaviors explicit. Beyond fostering psychological safety, direct supervisors can enhance learning from errors by providing timely feedback, being accessible and involved, providing guidance and elaborate feedback, and organizing joint evaluations. Our findings resonate with prior research by Goodman et al. (2004) and Mulder (2013), indicating that supervisors who provide specific information about performance facilitate a willingness to learn and engagement in learning activities. Furthermore, our findings support the notion that feedback becomes valuable for learning when it is provided in a timely fashion (van der Rijt et al., 2013). Additionally, participants reported that supervisors who made the effort to be regularly physically present, enabled professionals to engage in learning activities by being informed on errors promptly (Tucker \& Edmondson, 2003). Moreover, supervisors who organize joint evaluations have been found to foster professionals' learning from errors (Bligh et al., 2018). Based on our findings, we conclude that supervisors can enable engagement in learning activities directly as well as through psychological safety.

Our third research question focused on the supervisor behaviors that participants viewed as hindering engagement in learning from errors activities. In line with theoretical notions by Edmondson (2019) and Edmondson and Lei (2014), our findings confirm that the mere existence of psychological safety is not enough to initiate professionals' engagement in learning activities. When direct supervisors behave in ways that hinder learning activities, a perception of psychological safety is insufficient for effective learning from errors, mirroring extant findings on leader behavior in the wider learning literature. Supervisors who do not provide guidance and elaborate feedback hinder their supervisees' engagement in learning from errors activities by withholding necessary information. This finding echoes reviews by Hattie and Timperley (2007) and Shute (2008), which illustrate that simple performance feedback only becomes useful for learning when it provides learners with specific information on how and why the current task performance deviates from desired goals and/or standards. Similarly, supervisors who provide only delayed feedback impair learning through memory biases (Villado \& Arthur, 2013), and through the inability to connect feedback messages to existing knowledge (Bindal et al., 2011). Furthermore, supervisors who are inaccessible and uninvolved hinder engagement in learning activities such 
as help-seeking (Grohnert et al., 2019; van der Rijt et al., 2013). Finally, supervisors should organize joint evaluations of errors, because a lack of evaluation has been found to limit the impact of feedback on individual learning and professional development (Govaerts et al., 2013). We conclude that supervisors not only play a key role in enabling role professionals' learning from errors via creating a psychologically safe work environment, but they also need to actively create the opportunity for professionals to engage in individual and social learning from errors activities.

\section{Limitations and Implications for Future Research}

This study is subject to several limitations that impact the interpretation and generalizability of our results. First, this study was conducted within a single professional environment: auditing. Although our sample included audit professionals from different organizations and ranks, it is difficult to generalize our results to other contexts, due to the strict hierarchy, regulated activities, and the professionalized certification, training, and role expectations. Future studies may explore whether our findings can be replicated in work settings that differ in the degree of hierarchy. Second, our study is based on self-reported statements of participants. Therefore, when processing the interview data, the presence of participants' self-reporting biases and inaccuracies cannot be excluded, despite combining different perspectives and validating the coding scheme and application. Moreover, due to the self-report nature of the data we are unable to test for causal effects. Longitudinal and experimental research designs should be used in future research to reduce concerns regarding self-reporting biases and to help establish causality. Third, this study provides an overview of direct supervisor behaviors that relate to psychological safety and engagement in learning from errors behaviors. This study did not explore environmental constraints or enablers, and we did not test the effects of these behaviors on outcomes of learning from errors. These issues, along with the interaction of environmental factors and leader behaviors, are promising avenues for future research. Future research should examine whether supervisors' behavior in response to errors changes over time and across different subordinates, and under what conditions supervisors tend to invest time in providing elaborate feedback that helps professionals learn and develop their skills and knowledge. Moreover, future research should explore the role of supervisors' skills for providing helpful feedback and guidance in professionals' learning from errors. Literature suggests that supervisors might be experienced in their field of work, but might lack skills in giving feedback and guidance that help subordinates to learn from their errors (Mulder, 2013).

\section{Practical Implications}

The findings of this study have a number of practical implications for direct supervisors who want to promote professionals' learning from errors. Our findings confirm that supervisors have a direct influence on how safe their supervisees feel at work: the specific behaviors reported by our participants are concrete illustrations of how to create psychological safety. In accordance with Edmondson's (2019) metaphor of 'starting the car', supervisors can directly affect the engagement of their supervisees in learning from errors activities. Underlying these behaviors need to be a core value of fostering supervisees' learning and development so that supervisors can communicate with integrity that their errors are worth 
reflective thinking and analysis (Tucker \& Edmondson, 2003). We propose that supervisors need to assess the quality of their feedback and whether their feedback can contribute to professionals' learning and long-term work improvements. Supervisors can do this by asking their subordinates for feedback on their way of supervising. Asking subordinates for feedback helps supervisors evaluate subordinates' expectations regarding the frequency and developmental value of feedback, and it might provide supervisors with insights on how they can help their subordinates better realize their full learning potential (Baker et al., 2013). We recommend supervisors to evaluate how and to what extent their current organization enables or limits them in providing learning opportunities to their subordinates after they make an error in their work. As proposed by Nägele and Stalder (2019), this evaluation by supervisors can include a reflection on for instance the organizations' overall learning goals and the professionals' learning needs.

The results of our study provide some second-order implications for organizations. Organizations can encourage professionals in a supervisor position to provide timely and elaborate feedback to their subordinates by acknowledging its importance and actively rewarding this behavior. Moreover, organizations can support supervisors in creating learning opportunities for subordinates by allocating adequate learning resources (e.g. space and time) and prioritizing providing timely and elaborate feedback. A recent study by Westermann et al. (2015) in the audit setting concludes that coaching on the job is often not given priority over other competing demands (e.g. deadlines, client satisfaction) on a supervisors' time. To achieve this goal, organizations need to enable supervisors to acquire the skills necessary for providing valuable feedback that enhances professionals' learning from errors and to further their professional development (Milner et al., 2018; Mulder \& Ellinger, 2013). To foster learning from errors, supervisors need to have an understanding of their subordinates' learning needs and current limitations, they need to be able to target their feedback at the most salient error causes, focusing on factors under the control of the subordinate (Steelman \& Rutkowski, 2004). In addition, feedback needs to be given in a way that minimizes negative emotional reactions to feedback and to be able to mindfully process it, which may be achieved through different means for different subordinates (Steelman \& Wolfeld, 2018). Furthermore, supervisors can help professionals to learn and make improvements on the job by providing feedback that is explanatory and futureoriented (Zhou, 2003). This requires that organizations build a strong leadership development and support system, so that learning-oriented leaders are recruited, developed, and promoted consistently throughout the organization. Leaders who value learning from errors and display enhancing behaviors can directly influence the competence and performance of individuals and organizations alike.

\section{Appendix}

\section{Semi-structured interview (translated from Dutch to English)}

\section{Introduction}

My goal in this interview study is to better understand auditors' professionalism and which factors contribute to how they manage errors at work. This interview will last 
approximately one hour. Do you agree to me recording this interview in order to transcribe and analyze the data later on? All information you provide will be handled anonymously, please do not mention names of colleagues, clients, and/ or your firm during the interview. Do you have any questions before we start with the interview?

\section{Part 1: Describing a recent error experience}

Opening question: First, I would like to ask you what makes your daily job challenging? (Since our interviews involve a sensitive topic, we decided to open the interview with a general question to build rapport first.)

Due to the increasing pressure from regulators, and legislation, situations may arise in which you realize afterwards that something has not gone quite right. I would like to ask you to think back to a specific situation (that occurred in the past three months) during the audit process, in which something went wrong during the execution of your work for which you were responsible yourself. Consider a situation in which the audit procedures were carried out properly, but were found to be insufficient to rely on. Please describe a situation in which you were convinced that you were doing the right thing. However, during the review process, your direct supervisor provided you with negative feedback (e.g. an unintended deviation between the current state and the goal) and that you have not been able to achieve the desired result. How would you describe this experience?

- Detection of error: How did you discover that something went wrong during the audit process (detected by direct supervisor, yourself, the system)

- Causes of the error: What were the causes of this error? Why do you think that this happened?

- Consequences of errors: What were the consequences of the error that you just described?

- Other information?

\section{Part 2: Dealing with the error experience and engagement in learning activities}

- Emotions: Can you describe how you reacted after discovery of your error? What thoughts did you have?

- Engagement in learning activities: What have you done to prevent the same error from occurring?

\section{Part 3: The role of the supervisor in the error-related learning process}

- Perception of psychological safety: How did your supervisor react to your error? How does this affect you? How safe do you feel to talk openly with your supervisor about your error experience?

- Creating psychological safety: In your supervisor position, how do you ensure that supervisees feel safe to approach you for feedback, help and support after they made an error? 
- Role supervisor in professionals' engagement in learning activities: What was the role of your supervisor in preventing the same error from occurring?

- Supervisor role in inhibiting professionals' learning from errors and professional development: How would you have been helped better to prevent the same error from occurring again? What advice would you like to give to your direct supervisor?

- Supervisor role in facilitating professionals' learning from errors and professional development: What would you need from your supervisor to further improve the quality of your work and to prevent the same error from occurring? In your supervisor position, what have you done to ensure that professionals do not make the same error again?

- Other behaviors or processes?

Acknowledgments The authors would like to thank Christine Nolder of Suffolk University, Mary Kate Dodgson of Northeastern University and Wendy Nuis of Maastricht University for their support.

Code Availability Not applicable.

Funding This study was funded internally at Maastricht University and did not receive any additional funding. All research has been conducted in compliance with ethical standards at Maastricht University.

Data Availability Interviews were conducted anonymously; for questions, please contact the first author.

\section{Declarations}

Conflict of Interest The authors declare no conflict of interest.

Open Access This article is licensed under a Creative Commons Attribution 4.0 International License, which permits use, sharing, adaptation, distribution and reproduction in any medium or format, as long as you give appropriate credit to the original author(s) and the source, provide a link to the Creative Commons licence, and indicate if changes were made. The images or other third party material in this article are included in the article's Creative Commons licence, unless indicated otherwise in a credit line to the material. If material is not included in the article's Creative Commons licence and your intended use is not permitted by statutory regulation or exceeds the permitted use, you will need to obtain permission directly from the copyright holder. To view a copy of this licence, visit http://creativecommons.org/licenses/by/4.0/.

\section{References}

Anselmann, V., \& Mulder, R. H. (2018). Learning from errors in insurance companies. Journal of Management Development, 37(2), 138-148. https://doi.org/10.1108/JMD-06-2017-0211.

Ater, B., Gimbar, C., Jenkins, J. G., Saucedo, G., \& Wright, N. S. (2019). Audit roles and the review process: Workpaper preparers' and reviewers' differing perspectives. Managerial Auditing Journal, 34(4), 434 457. https://doi.org/10.1108/MAJ-05-2018-1896.

Baker, A., Perreault, D., Reid, A., \& Blanchard, C. M. (2013). Feedback and organizations: Feedback is good, feedback-friendly culture is better. Canadian Psychology, 54(4), 260-268. https://doi.org/10.1037/ a0034691.

Bamberger, P. (2009). Employee help-seeking: Antecedents, consequences and new insights for future research. Research in Personnel and Human Resources Management, 28, 49-98. https://doi.org/10. 1108/S0742-7301(2009)0000028005. 
Bauer, J. (2008). Learning from Errors at Work Studies on Nurses' Engagement in Error-Related Learning Activities. Doctoral dissertation, University of Regensburg. Retrieved from http://www.opus-bayern.de/ uniregensburg/volltexte/2008/990.

Bauer, J., \& Mulder, R. H. (2007). Modelling learning from errors in daily work. Learning in Health and Social Care, 6(3), 121-133. https://doi.org/10.1111/j.1473-6861.2007.00150.x.

Bauer, J., \& Mulder, R. H. (2013). Engagement in learning after errors at work: Enabling conditions and types of engagement. Journal of Education and Work, 26(1), 99-119. https://doi.org/10.1080/13639080.2011. 573776.

Baumgartner, A., \& Seifried, J. (2014). Error climate and how individuals deal with errors in the workplace. In C. Harteis, A. Rausch, \& J. Seifried (Eds.), Discourses on professional learning (pp. 95-111). Springer.

Billett, S. (2004). Workplace participatory practices: Conceptualising workplaces as learning environments. Journal of Workplace Learning, 16(6), 312-324. https://doi.org/10.1108/13665620410550295.

Bindal, T., Wall, D., \& Goodyear, H. M. (2011). Trainee doctors' views on workplace-based assessments: Are they just a tick box exercise? Medical Teacher, 33(11), 919-927. https://doi.org/10.3109/0142159X. 2011.558140 .

Bligh, M. C., Kohles, J. C., \& Yan, Q. (2018). Leading and learning to change: The role of leadership style and mindset in error learning and organizational change. Journal of Change Management, 18(2), 116141. https://doi.org/10.1080/14697017.2018.1446693.

Cannon, M. D., \& Edmondson, A. C. (2005). Failing to learn and learning to fail (intelligently): How great organizations put failure to work to innovate and improve. Long Range Planning, 38(3 SPEC. ISS.), 299319. https://doi.org/10.1016/j.lrp.2005.04.005.

Carmeli, A., Tishler, A., \& Edmondson, A. C. (2012). CEO relational leadership and strategic decision quality in top management teams: The role of team trust and learning from failure. Strategic Organization, 10(1), 31-54. https://doi.org/10.1177/1476127011434797.

Cusin, J., \& Goujon-Belghit, A. (2019). Error reframing: Studying the promotion of an error management culture. European Journal of Work and Organizational Psychology, 28(4), 510-524. https://doi.org/10. 1080/1359432X.2019.1623786.

Dahlin, K., Chuang, Y.-T., \& Roulet, T. (2018). Opportunity, motivation and ability to learn from failures and errors: Review, synthesis, and the way forward. Academy of Management Annals, 12(1), 252-277. https:// doi.org/10.5465/annals.2016.0049.

Deng, B. H., Bligh, M. C., \& Kohles, J. C. (2010). To err is human, to lead is divine? The role of leaders in learning from workplace mistakes. In B. Schyns \& T. Hansbrough (Eds.), When leadership goes wrong: Destructive leadership, mistakes and ethica (pp. 445-475).

Detert, J., R., Burris, E., R. (2007). Leadership Behavior and Employee Voice: Is the Door Really Open?. Academy of Management Journal, 50 (4), 869-884.

Edmondson, A. C. (1999). Psychological safety and learning behavior in work teams. Administrative Science Quarterly, 44(2), 350-383. https://doi.org/10.2307/2666999.

Edmondson, A. C. (2011). Strategies for learning from failure. Harvard Business Review, 89(4).

Edmondson, A. C. (2019). The fearless organization: Creating psychological safety in the workplace for learning, innovation, and growth. John Wiley \& Sons.

Edmondson, A. C., \& Lei, Z. (2014). Psychological safety: The history, renaissance, and future of an interpersonal construct. Annual Review of Organizational Psychology and Organizational Behavior, 1, 23-43. https://doi.org/10.1146/annurev-orgpsych-031413-091305.

Eraut, M., Alderton, J., Cole, G., \& Senker, P. (1998). Development of knowledge and skills in employment. (research report no. 5). Sussex: University of Sussex, Institute of Education.

Farnese, M. L., Zaghini, F., Caruso, R., Fida, R., Romagnoli, M., \& Sili, A. (2019). Managing care errors in the wards: The contribution of authentic leadership and error management culture. Leadership and Organization Development Journal, 40(1), 17-30. https://doi.org/10.1108/LODJ-04-2018-0152.

Flanagan, J. C. (1954). The critical incident technique. Psychological Bulletin, 51(4), 327-358.

Francis, J. J., Johnston, M., Robertson, C., Glidewell, L., Entwistle, V., Eccles, M. P., \& Grimshaw, J. M. (2010). What is an adequate sample size? Operationalising data saturation for theory-based interview studies. Psychology and Health, 25(10), 1229-1245. https://doi.org/10.1080/08870440903194015.

Frazier, M. L., Fainshmidt, S., Klinger, R. L., Pezeshkan, A., \& Vracheva, V. (2017). Psychological safety: A meta-analytic review and extension. Personnel Psychology, 70(1), 113-165. https://doi.org/10.1111/peps. 12183.

Frese, M., \& Keith, N. (2015). Action errors, error management, and learning in organizations. Annual Review of Psychology, 66(1), 661-687. https://doi.org/10.1146/annurev-psych-010814-015205.

Frese, M., \& Zapf, D. (1994). Action as the core of work psychology. Handbook of Industrial and Organizational Psychology, 4. 
Gartmeier, M., Bauer, J., Gruber, H., \& Heid, H. (2008). Negative knowledge: Understanding professional learning and expertise. Vocations and Learning, 1(2), 87-103. https://doi.org/10.1007/s12186-008-90061.

Gibbins, M., \& Trotman, K. T. (2002). Audit review: Managers' interpersonal expectations and conduct of the review. Contemporary Accounting Research, 19(3), 411-444. https://doi.org/10.1506/J519-5LVUJTMQ-YYJ7.

Goodman, J. S., Wood, R. E., \& Hendrickx, M. (2004). Feedback specificity, exploration, and learning. Journal of Applied Psychology, 89(2), 248-262. https://doi.org/10.1037/0021-9010.89.2.248.

Govaerts, M. J. B., van de Wiel, M. W. J., \& van der Vleuten, C. P. M. (2013). Quality of feedback following performance assessments: Does assessor expertise matter? European Journal of Training and Development, 37(1), 105-125. https://doi.org/10.1108/03090591311293310.

Grohnert, T., Meuwissen, R. H. G., \& Gijselaers, W. H. (2019). Enabling young professionals to learn from errors - the role of a supportive learning climate in crossing help network boundaries. Vocations and Learning, 12, 217-243. https://doi.org/10.1007/s12186-018-9206-2.

Gronewold, U., \& Donle, M. (2011). Organizational error climate and auditors' predispositions toward handling errors. Behavioral Research in Accounting, 23(2), 69-92. https://doi.org/10.2308/bria-10061.

Gronewold, U., Gold, A., \& Salterio, S. E. (2013). Reporting self-made errors: The impact of organizational error-management climate and error type. Journal of Business Ethics, 117(1), 189-208. https://doi.org/10. 1007/s10551-012-1500-6.

Harteis, C., Bauer, J., \& Gruber, H. (2008). The culture of learning from mistakes: How employees handle mistakes in everyday work. International Journal of Educational Research, 47(4), 223-231. https://doi. org/10.1016/j.ijer.2008.07.003.

Hattie, J., \& Timperley, H. (2007). The power of feedback. Review of Educational Research, 77(1), 81-112. https://doi.org/10.3102/003465430298487.

Hetzner, S., Gartmeier, M., Heid, H., \& Gruber, H. (2011). Error orientation and reflection at work. Vocations and Learning, 4(1), 25-39. https://doi.org/10.1007/s12186-010-9047-0.

Hirak, R., Peng, A. C., Carmeli, A., Schaubroeck, J. M. (2012). Linking leader inclusiveness to work unit performance: The importance of psychological safety and learning from failures. The Leadership Quarterly, 23 (1), 10-7117.

Hsieh, H.-F., \& Shannon, S. E. (2005). Three approaches to qualitative content analysis. Qualitiative Health Research, 15(9), 1277-1288. https://doi.org/10.1177/1049732305276687.

Jeppesen, K. K. (2007). Organizational risk in large audit firms. Managerial Auditing Journal, 22(6), 590603. https://doi.org/10.1108/02686900710759398.

Keith, N., \& Frese, M. (2005). Self-regulation in error management training: Emotion control and metacognition as mediators of performance effects. Journal of Applied Psychology, 90(4), 677-691. https://doi. org/10.1037/0021-9010.90.4.677.

Keith, N., \& Frese, M. (2011). Enhancing firm performance and innovativeness through error management culture. In N. M. Ashkanasy, C. P. M. Wilderom, \& M. F. Peterson (Eds.), The handbook of organizational culture and climate (2nd ed., pp. 137-157). SAGE.

Koeslag-Kreunen, M. G. M., Van der Klink, M. R., Van den Bossche, P., \& Gijselaers, W. H. (2018). Leadership for team learning: The case of university teacher teams. Higher Education, 75(2), 191-207. https://doi.org/10.1007/s10734-017-0126-0.

Lei, Z., Naveh, E., \& Novikov, Z. (2016). Errors in organizations: An integrative review via level of analysis, temporal dynamism, and priority lenses. Journal of Management, 42(5), 1315-1343. https://doi.org/10. $1177 / 0149206316633745$.

Leicher, V., \& Mulder, R. H. (2016). Individual and contextual factors influencing engagement in learning activities after errors at work: A replication study in a German retail Bank. Journal of Work, 2(1), 66-80. https://doi.org/10.1108/MRR-09-2015-0216.

Leicher, V., Mulder, R. H., \& Bauer, J. (2013). Learning from errors at work: A replication study in elder care nursing. Vocations and Learning, 6(2), 207-220. https://doi.org/10.1007/s12186-012-9090-0.

Marsick, V. J., Watkins, K.E. (2003). Demonstrating the Value of an Organization's Learning Culture: The Dimensions of the Learning Organization Questionnaire. Advances in Developing Human Resources, 5 (2), 132-151.

Miles, M. B., \& Huberman, A. M. (1994). Qualitative data analysis: An expanded sourcebook. Sage Publications Inc. 
Milner, J., McCarthy, G., \& Milner, T. (2018). Training for the coaching leader: How organizations can support managers. Journal of Management Development, 37(2), 188-200. https://doi.org/10.1108/JMD04-2017-0135.

Mulder, R. H. (2013). Exploring feedback incidents, their characteristics and the informal learning activities that emanate from them. European Journal of Training and Development, 37(1), 49-71. https://doi.org/ $10.1108 / 03090591311293284$.

Mulder, R. H. (2015). Using critical incidents and vignette technique in HRD research to investigate learning activities and behaviour at work. In M. N. K. Saunders \& P. Tosey (Eds.), Handbook of research methods on human resource development (Vol. 26, pp. 252-256). Edward Elgar Publishing. https://doi.org/10. 1136/bmjqs-2015-004853.

Mulder, R. H., \& Ellinger, A. D. (2013). Perceptions of quality of feedback in organizations: Characteristics, determinants, outcomes of feedback, and possibilities for improvement: Introduction to a special issue. European Journal of Training and Development, 37(1), 4-23. https://doi.org/10.1108/ 03090591311293266.

Nägele, C., \& Stalder, B. E. (2019). Motivation and engagement of learners in organizations. In S. McGrath, M. Mulder, J. Papie, \& R. Suart (Eds.), Handbook of Vocational Education and Training (pp. 1-15). Springer. https://doi.org/10.1007/978-3-319-49789-1_106-1.

Nellen, L. C., Gijselaers, W. H., \& Grohnert, T. (2019). A meta-analytic literature review on organizationlevel drivers of team learning. Human Resource Development Review., 19, 152-182. https://doi.org/10. $1177 / 1534484319894756$.

Nembhard, I. M., \& Edmondson, A. C. (2006). Making it safe: The effects of leader inclusiveness and professional status on psychological safety and improvement efforts in health care teams. Journal of Organizational Behavior, 27(7), 941-966. https://doi.org/10.1002/job.413.

Newman, A., Donohue, R., \& Eva, N. (2017). Psychological safety: A systematic review of the literature. Human Resource Management Review, 27(3), 521-535. https://doi.org/10.1016/j.hrmr.2017.01.001.

Rasmussen, J. (1987). Cognitive control and human error mechanisms. In J. Rasmussen, K. Duncan, \& J. Leplat (Eds.), New technology and human error (pp. 53-62). Wiley.

Reason, J. (1995). Understanding adverse events: Human factors. Quality in health care : QHC, 4(2), 80-89. https://doi.org/10.1136/qshc.4.2.80.

Rodriguez, M. A., \& Griffin, M. A. (2009). From error prevention to error learning: The role of error management in global leadership. Advances in Global Leadership, 5, 93-112. https://doi.org/10.1108/ S1535-1203(2009)0000005008.

Rybowiak, V., Garst, H., Frese, M., \& Batinic, B. (1999). Error orientation questionnaire (EOQ): Reliability, validity, and different language equivalence. Journal of Organizational Behavior, 20(4), 527-547. https:// doi.org/10.1002/(SICI)1099-1379(199907)20:4<527::AID-JOB886>3.0.CO;2-G.

Schreier, M. (2012). Qualitative content analysis in practice. SAGE.

Seckler, C., Gronewold, U., \& Reihlen, M. (2017). An error management perspective on audit quality: Toward a multi-level model. Accounting, Organizations and Society, 62(1), 21-42. https://doi.org/10.1016/j.aos. 2017.08.004.

Seifried, J., \& Höpfer, E. (2013). The perception of error in production plants of a chemical organisation. Vocations and Learning, 6(2), 159-185. https://doi.org/10.1007/s12186-012-9081-1.

Shute, V. J. (2008). Focus on formative feedback. Review of Educational Research, 78(1), 153-189.

Simons, P. R.-J., \& Ruijters, M. C. P. (2004). Learning professionals: Towards an in- tegrated model. In H. P. A. Boshuizen, R. Bromme, \& H. Gruber (Eds.), Professional learning: Gaps and transitions on the way from novice to expert (pp. 207-229). .

Steelman, L. A., \& Rutkowski, K. A. (2004). Moderators of employee reactions to negative feedback. Journal of Managerial Psychology, 19(1), 6-18. https://doi.org/10.1108/02683940410520637.

Steelman, L. A., \& Wolfeld, L. (2018). The manager as coach: The role of feedback orientation. Journal of Business and Psychology, 33(1), 41-53. https://doi.org/10.1007/s10869-016-9473-6.

Trotman, K. T., Bauer, T. D., \& Humphreys, K. A. (2015). Group judgment and decision making in auditing: Past and future research. Accounting, Organizations and Society, 47, 56-72. https://doi.org/10.1016/j.aos. 2015.09.004

Tucker, A. L., \& Edmondson, A. C. (2003). Why hospitals don't learn from failures: organizational and psychological dynamics that inhibit system change. California Review Management, 45, 55-72. 
van der Rijt, J., van den Bossche, P., van de Wiel, M. W. J., de Maeyer, S., Gijselaers, W. H., \& Segers, M. S. R. (2013). Asking for help: A relational perspective on help seeking in the workplace. Vocations and Learning, 6(2), 259-279. https://doi.org/10.1007/s12186-012-9095-8.

van Woerkom, M. (2003). Critical reflection at work. Bridging individual and organisational learning. Enschede: PrintPartners.

Villado, A. J., \& Arthur, W. J. (2013). The comparative effects of subjective and objective after-action reviews on team performance on a complex task. Journal of Applied Psychology, 98, 514-528.

Westermann, K. D., Bedard, J. C., \& Earley, C. E. (2015). Learning the "craft" of auditing: A dynamic view of auditors' on-the-job learning. Contemporary Accounting Research, 32(3), 864-896. https://doi.org/10. 1111/1911-3846.12107.

Ye, Q., Wang, D., \& Li, X. (2018). Promoting employees' learning from errors by inclusive leadership: Do positive mood and gender matter? Baltic Journal of Management, 13(1), 125-142. https://doi.org/10. 1108/BJM-05-2017-0160.

Zhao, B. (2011). Learning from errors: The role of context, emotion, and personality. Journal of Organizational Behavior, 32(3), 435-463. https://doi.org/10.1002/job.696.

Zhao, B., \& Olivera, F. (2006). Error reporting in organizations. Academy of Management, 31(4), 1012-1030.

Zhao, B., Seifried, J., \& Sieweke, J. (2018). Trainers' responses to errors matter in trainees' learning from errors: Evidence from two studies. Journal of Managerial Psychology, 33(3), 279-296. https://doi.org/10. 1108/JMP-10-2017-0364.

Zhao, B., Emby, C., \& Sieweke, J. (2019). Audit senior modeling fallibility: The effects of reduced error strain and enhanced error-related self-efficacy on audit juniors' responses to self-discovered errors. Behavioral Research in Accounting, 31(2), 17-30.

Zhou, J. (2003). When the presence of creative coworkers is related to creativity: Role of supervisor close monitoring, developmental feedback, and creative personality. Journal of Applied Psychology, 88(3), 413-422. https://doi.org/10.1037/0021-9010.88.3.413.

Publisher's Note Springer Nature remains neutral with regard to jurisdictional claims in published maps and institutional affiliations.

Laura Smeets , Department of Educational Research and Development, School of Business and Economics, Maastricht University, the Netherlands. Laura Smeets is $\mathrm{PhD}$ candidate at the Department of Educational Research and Development at Maastricht University School of Business and Economics, email: lh.smeets@maastrichtuniversity.nl. Her research interests include workplace learning, especially from errors, expertise development, as well as managerial coaching, and developmental feedback.

Wim H. Gijselaers , Department of Educational Research and Development, School of Business and Economics, Maastricht University, the Netherlands. Wim H. Gijselaers is Full Professor of Educational Research in the Department of Educational Research and Development at Maastricht University School of Business and Economics; email w.gijselaers@maastrichtuniversity.nl. His research focuses on professional development in the business domain, and team dynamics.

Roger H. G. Meuwissen, Department of Accounting \& Information Management, School of Business and Economics, Maastricht University, the Netherlands. Roger Meuwissen is Full Professor of Control and Auditing at Mastricht University School of Business and Economics; email r.meuwissen@maastrichtuniversity.nl. His research revolves around the areas of audit quality and auditor decision-making.

Therese Grohnert, Department of Educational Research and Development, School of Business and Economics, Maastricht University, the Netherlands. Therese Grohnert is assistant professor at the Department of Educational Research and Development at Maastricht University School of Business and Economics, email:t.grohnert@maastrichtuniversity.nl. Her research interests include workplace learning and team learning for effective judgment and decision-making. 